DOI: https://doi.org/10.30749/2594-8261.v3n1p34-40

\title{
A CURA E A FÁBULA DE HIGINO: UMA COMPREENSÃO EXISTENCIAL DO DIREITO
}

\section{THE CURE AND THE FABLE OF HYGINO: AN EXISTENTIAL UNDERSTANDING OF THE LAW}

Cleyson de Moraes Mello*

Resumo: A hermenêutica filosófica em Heidegger assume um viés transformador. Daí a necessidade de compreender o fundamento do direito a partir da cura (cuidado) tratado no § 41 da obra Ser e Tempo.

Palavras-chave: Heidegger. Ser-no-mundo. Dasein.

Abstract: Heidegger's philosophical hermeneutics takes on a transformative bias. Hence the need to understand the foundation of right from the cure (care) treated in $\S$ 41 of the work Being and Time.

Keywords: Heidegger. Being-in-the-world. Dasein.

\footnotetext{
* Professor Adjunto da Faculdade de Direito da UERJ. Coordenador da Graduação em Direito da Faculdade de Direito da UERJ. Vice-Chefe do Departamento de Teorias e Fundamento do Direito da Faculdade de Direito da UERJ. Professor do PPGD da UERJ e UVA. Diretor Adjunto da Faculdade de Direito de Valença - RJ; Professor Titular da Universidade Estácio de Sá. E-mail: profcleysonmello@hotmail.com.
} 


\section{INTRODUÇÃO}

A compreensão da Constituição é um existencial. A compreensão não pode abrir mão do modo de ser do Dasein (ser-ai), uma vez que não pode ser um ente simplesmente dado, "resultante da colagem de pedaços" (HEIDEGGER, 2004, p. 94), mas deve se dar, em sua totalidade, pela sua compreensão existenciária. Assim, o julgador deve compreender a Constituição, nada menos, "do que da exigência de projetar esses fenômenos existenciais sobre as possibilidades existenciárias já delineadas e pensá-las, existencialmente, 'até o fim'." (HEIDEGGER, 2004, p. 94) Dessa maneira, a compreensão existencial da Constituição anuncia o seu caráter mais originário e fundamental. E o mais importante com isso, é que a decisão judicial no sentido existenciariamente possível e própria, deixa de lado o seu caráter de uma construção arbitrária.

Do ponto de vista ontológico, a Constituição deve ser des(velada) a partir do ser-aí (Dasein). Mais do que isso: "seu 'teor' não se funda na substancialidade de uma substância e sim na 'autoconsistência' do si-mesmo existente e cujo ser foi concebido como cura." (HEIDEGGER, 2004, p. 95). O fenômeno do si-mesmo está incluído na cura (cuidado, sorge, preocupação), necessitando, pois, de uma compreensão originária e própria da Constituição.

\section{O SER DO DASEIN (PRE-SENÇA) COMO CURA}

É no $§ 41$ de Ser e Tempo que Heidegger trata da cura como o ser da presença (Dasein). A cura (cuidado, sorge, preocupação) é uma articulação complexa constituída por três elementos: existencialidade, facticidade e de-cadência. (HEIDEGGER, 2002, p. 255). Estes caracteres ontológicos do Dasein se desvelam sob a forma de uma totalidade articulada, uma espécie de nexo originário de um todo estrutural. Melhor dizendo: é neste contexto de completude dos elementos ontológicos fundamentais do Dasein que será possível apreender ontologicamente o seu ser enquanto tal. (HEIDEGGER, 2002, p. 255-256).

Daí a importância da hermenêutica e da compreensão, uma vez que é na constituição ontológica da compreensão que se evidencia o poder-se e o estar 
lançado. Heidegger afirma que "em seu ser, a pre-sença já sempre se conjugou com uma possibilidade de si mesma." (HEIDEGGER, 2002, p. 256). É neste horizonte que a estrutura totalizante do Dasein encontra seu condição de possibilidade, permitindo, pois, a essa tripla estrutura desvelar no modo de sua unidade. A cura abrange a unidade dessas determinações ontológicas. (HEIDEGGER, 2002, p. 257).

Importante lembrar que esta estrutura ontológica não está relacionada a um binômio sujeito-objeto (relação de objetos com um sujeito), senão a uma estrutura fenomenalmente articulada com seu todo originário. A cura é, pois, em sua totalidade indivisível e "toda tentativa de reconstrução ou recondução do fenômeno da cura a atos ou impulsos particulares tais como querer ou desejar, propensão ou tendência converte-se em fracasso." (HEIDEGGER, 2002, p. 258).

A cura precede a si mesma e é neste preceder-se a si mesma que subsiste a sua condição de possibilidade ontológico-existencial. (HEIDEGGER, 2002, p. 258).

É neste sentido que a decisão judicial não pode estar desvinculada do seu ponto de vista ontológico. É necessário que o julgador tenha horizontes, desvinculado de uma visão solipsista. Ao decidir, só se compreende um caso concreto decidendo se projetado em suas possibilidades como ente a ser tratado na cura. É por isso que ao decidir, se decidi algo que se quer, algo que já foi determinado a partir daquilo emfunção-de (o preceder a si mesmo). Nesta condição de possibilidade ontológica do ato de decidir são constitutivos e essenciais: a) uma abertura prévia (o preceder a si mesmo); b) a abertura ao caso concreto decidendo (o mundo como algo que já se é) e; c) o projeto de compreensão do Dasein numa condição de possibilidade (poderser).

Heidegger ensina que como fato o projetar-se do Dasein (ser-ai, pre-sença) está sempre junto a um mundo descoberto e é a partir deste que o projetar-se recebe as suas possibilidades. (HEIDEGGER, 2002, p. 259). É isto que restringe antecipadamente as possibilidades de escolha no âmbito da decisão judicial.

A decisão judicial em sua totalidade não pode ser realizada de modo superficial a partir de seus elementos primários ônticos, senão reconduzidas a partir de uma questão ontológica fundamental, mais profunda, articulada pela totalidade da multiplicidade estrutural da cura. Neste contexto, a cura permite ao magistrado decidir e olhar a constituição de modo ôntico-existenciário, ou seja, a partir dos fundamentos 
ontológicos adequados lastreados na essência da constituição. Neste sentido, a compreensão ontológico-existencial da constituição pode causar uma espécie de estranheza, mormente quando se desconhece e não se compreende a cura. $\mathrm{Na}$ maioria das vezes a decisão judicial e a compreensão da constituição é realizada apenas no viés ôntico e não ontológico.

\title{
3 A COMPREENSÃO EXISTENCIAL (ONTOLÓGICA) DA CONSTITUIÇÃO E A FÁBULA DE HIGINO
}

A compreensão ontológica não é pura invenção. (HEIDEGGER, 2002, p. 263). A auto interpretação do Dasein como "cura" foi apresentado por Heidegger em sua obra Ser e Tempo, com base na fábula de Higino (Faust und die Sorge). Vejamos:

\begin{abstract}
Certa vez, atravessando um rio, "cura" viu um pedaço de terra ardilosa: cogitando, tomou um pedaço e começou a lhe dar forma. Enquanto refletia sobre o que criara, interveio Júpiter. A cura pediu lhe que desse espírito à forma de argila, o que Ihe fez de bom grado. Como a cura quis então dar seu nome ao que tinha dado forma, Júpiter a proibiu e exigiu que fosse dado o nome. Enquanto "Cura" e Júpiter disputavam sobre o nome, surgiu também a terra (tellus) querendo dar o seu nome, uma vez que havia fornecido um pedaço de seu corpo. Os disputantes tomaram Saturno como árbitro. Saturno pronunciou a seguinte decisão, aparentemente equitativa: "Tu, Júpiter, por teres dado o espírito, deves receber na morte o espírito e tu, terra, por teres dado o corpo, deves receber o corpo. Como, porém, foi a "cura" quem primeiro o formou, ele deve pertencer à 'cura' enquanto viver. Como, no entanto, sobre o nome há disputa, ele deve ser chamar 'homo', pois foi feito de humus (terra)". (HEIDEGGER, 2002, p. 263).
\end{abstract}

Neste sentido, a cura é vista "como aquilo a que pertence a pre-sença humana 'enquanto vive'. Heidegger afirma que determinação pré-ontológica da essência do homem expressa na fábula acima desvela, desde o início, o modo de ser em que predomina seu percurso temporal no mundo. (HEIDEGGER, 2002, p. 264). Assim, a cura se caracteriza pela historicidade que deve ser guiada ontologicamente.

Daí que a essência da Constituição está diretamente relacionada a sua "constituição ontológica" sempre subjacente. Isto só se torna ontologicamente possível desde que ela possa ser interpelada e lida como cura. A condição de possibilidade existencial da Constituição tida como "cuidado com a vida e com o 
homem" deve ser sempre compreendida como cura em seu sentido mais originário, isto é, em seu sentido ontológico.

A decisão judicial deve, pois, possuir uma envergadura de cunho preontológico da essência do homem enquanto ser-no-mundo. Melhor dizendo: cabe ao julgador realizar uma interpretação do caso concreto decidendo, a partir de um conceito existencial de cura.

A compreensão existencial da Constituição é a própria abertura do ser-nomundo. Toda a decisão judicial deve ser derivada dessa compreensão existencial, que é a própria luz, iluminação, abertura, clareira, revelação do ser-aí, Alethéia.

Considerando que a compreensão é um existencial, não existe explicação sem a prévia compreensão. Melhor dizendo: o sentido alcançado pela explicação já nos é dado, na própria explicação, ou seja, o sentido faz parte da própria estrutura prévia da compreensão. A compreensão e a explicação constituem existencialmente a pre-sença (ser-aí).

É através do método fenomenológico que as estruturas do ser-aí são explicitadas e que trazem em si a possibilidade de antecipação do sentido do ser pela pré-compreensão. Como dito acima, o sentido da pre-sença é dado pela temporalidade (Zeitlichkeit), ou seja, o tempo é o ponto de partida do qual a presença (ser-ai) sempre compreende e interpreta o seu ser. Dessa forma, o ser-aí é de tal modo que realiza uma compreensão do ser no horizonte do tempo. Vale lembrar que a temporalidade, neste caso, não é a representação tradicional do tempo (para Heidegger este seria o tempo inautêntico), senão uma temporalidade autêntica. É dessa forma que, em Ser e Tempo, Hedeigger sustenta a tese da Pre-sença $e$ Temporalidade (Segunda Seção de Ser e Tempo) que faz desmoronar radicalmente a equivalência metafísica entre ser e eternidade.

Frise-se que a abertura do ser-aí, ou seja, o ser do ser-aí é a preocupação (cura, sorge). Essa é a luz que constitui a luminosidade da pre-sença, isto é, aquilo que o torna "aberto" e também "claro" para si mesmo. É a cura que se funda toda abertura do pre e a temporalidade ekstática que o ilumina originariamente. Heidegger afirma que somente partindo do enraizamento da pre-sença na temporalidade que se consegue penetrar na possibilidade existencial do fenômeno, ser-no-mundo, que, no 
começo da analítica da pre-sença, fez-se conhecer como constituição fundamental. (HEIDEGGER, 2002, p. 150)

A abertura essencial do ser do homem é chamada cuidado, preocupação e o sentido propriamente temporal da existência enquanto modo de ser humano é a temporalidade.

Assim, Heidegger propõe a tese da finitude do tempo original, em detrimento à tese clássica da infinitude do tempo da natureza. Assim, podemos dizer que não há ser nem tempo senão na medida em que há Dasein. O Dasein dá a si mesmo o seu tempo. O fundamento ontológico originário da existencialidade da pre-sença é a temporalidade. A totalidade das estruturas do ser da pre-sença articuladas na cura só se tornará existencialmente compreensível a partir da temporalidade. (HEIDEGGER, 2004, p. 13) Portanto, é na temporalidade que Heidegger vai buscar o sentido da presença (ser-aí), isto é, da preocupação. O filósofo afirma em Ser e Tempo

Se a temporalidade constitui o sentido ontológico originário da presença, onde está em jogo o seu próprio ser, então a cura deve precisar de 'tempo' e, assim, contar com o 'tempo'. A temporalidade da presença constrói a 'contagem do tempo'. O 'tempo' nela experimentado é o aspecto fenomenal mais imediato da temporalidade. Dela brota a compreensão cotidiana e vulgar do tempo. E essa se desdobra, formando o conceito tradicional de tempo. (HEIDEGGER, 2004, p. 1314).

A compreensão do ser é tornada possivel mediante a temporalidade ekstática do Dasein, ou seja, o tempo passa a ser o locus da compreensão do Dasein. É, com efeito, no $\S 65$ de Ser e Tempo que a temporalidade é revelada como constituindo o sentido do cuidado, sorge, cura. Heidegger afirma que "enquanto cura, a totalidade ontológica da pre-sença diz: preceder-se-a-si-mesma-em (um mundo) enquanto serjunto-a (entes que vêm ao encontro dentro do mundo)." (HEIDEGGER, 2004, p. 121). Assim o filósofo fixou a articulação da estrutura originária da cura na temporalidade. Isso quer dizer que o Dasein (pre-sença) nunca perde a sua integralidade; que ela perdura no tempo, porque ele é formado por momentos inseparáveis uns dos outros. Daí Heidegger falar em estrutura do ser-aí. Esta estrutura fundamental é chamada ser-no-mundo.

Pertence à estrutura ontológica da pre-sença uma compreensão do ser. É sendo que a pre-sença está aberta para si mesma em seu ser. Há que se buscar uma 
abertura mais abrangente e mais originária dentro da própria pre-sença (Dasein). (HEIDEGGER, 2002, p. 245).

Portanto, não é no terreno da quotidianidade que vamos conseguir encontrar a unidade do Dasein (pre-sença). Isso porque a interpretação cotidiana da pre-sença encobre onticamente o ser próprio da pre-sença. (HEIDEGGER, 2004, p. 104). Assim, o modo de ser da pre-sença exige uma interpretação ontológica. A interpretação ontológica projeta o ente preliminarmente dado em seu próprio ser, de modo a chegar ao conceito de sua estrutura. Assim, originariamente constituída pela cura, a presença (Dasein) já sempre precede-a-si-mesma.

Desse modo, o pensamento heideggeriano caminha no sentido de analisar o homem não como um ente em meio aos outros entes (estrutura ôntica), mas procura analisar o homem a partir da abertura que nele é a própria manifestação do ser.

\section{REFERÊNCIAS}

HEIDEGGER, Martin. O fim da Filosofia ou a questão do pensamento. Tradução Ernildo Stein. São Paulo: Livraria Duas Cidades, 1972.

HEIDEGGER, Martin. Seminários de Zollikon. Tradução Gabriela Arnhold e Maria de Fátima de Almeida Prado. Petrópolis: Vozes, 2001.

HEIDEGGER, Martin. Ser e Tempo: parte I. Tradução Marcia Sá Cavalcante Schuback.12.ed. Petrópolis: Vozes, 2002.

HEIDEGGER, Martin. Ser e Tempo: parte II. Tradução Marcia Sá Cavalcante Schuback. 11.ed. Petrópolis: Vozes, 2004. 